\title{
Alterations in circadian/seasonal rhythms and vegetative functions are related to suicidality in DSM-5 PTSD
}

\author{
Liliana Dell'Osso ${ }^{1}$, Gabriele Massimetti ${ }^{1}$, Ciro Conversano ${ }^{1}$, Carlo Antonio Bertelloni' ${ }^{1}$, Mauro Giovanni Carta ${ }^{2}$, \\ Valdo Ricca ${ }^{3}$ and Claudia Carmassi ${ }^{1 *}$
}

\begin{abstract}
Background: Alterations in rhythmicity and vegetative functions have been reported as correlates of suicidality, particularly in patients with mood disorders. No investigation has addressed their impact on patients with posttraumatic stress disorder (PTSD). Aim of the present study was to fulfill this gap.

Methods: Sixty-five out- and inpatients with DSM-5 PTSD were assessed by using the Mood Spectrum-Self ReportLifetime Version (MOODS-SR), a questionnaire for lifetime mood spectrum symptomatology including alterations in circadian/seasonal rhythms and vegetative functions. Six items of the MOODS-SR were combined and dichotomized to assess suicidal ideation and/or attempts.
\end{abstract}

Results: Significant and positive associations were found between symptoms of lifetime dysregulations in rhythmicity and vegetative functions and suicidal ideation and/or attempts. All MOODS-SR sub-domains (rhythmicity, sleep, appetite/weight, sexual function, physical symptoms) were associated with an increased likelihood of suicidal ideation, but only changes in appetite/weight were associated with greater odd ratios of suicide attempts (OR $=2.099,95 \%$ Cl 1.148-3.841).

Conclusions: Our results suggest that lifetime dysregulations in rhythmicity and vegetative functions may represent correlates of suicidality in patients with DSM-5 PTSD.

Keywords: Rhythmicity, PTSD, Suicide attempts, Suicidal ideation, Vegetative functions

\section{Background}

Post-traumatic stress disorder (PTSD) has been progressively investigated in the general population affected by different types of trauma and there is agreement on its tendency to a chronic course and high risk for suicide [1-9]. Data from the National Comorbidity Survey [1] showed six folds higher rates of suicide attempts in PTSD patients with respect to demographically matched control subjects.

In recent years, increasing interest has been devoted to the relationship between dysregulations in both "rhythmicity" (such as sensitivity to seasonal and circadian rhythm and weather conditions) and vegetative functions (such as

\footnotetext{
* Correspondence: ccarmassi@gmail.com

${ }^{1}$ Section of Psychiatry, Department of Clinical and Experimental Medicine, University of Pisa, Via Roma 67, Pisa 56126, Italy

Full list of author information is available at the end of the article
}

sleep, appetite, sexual functions and menstrual cycle), and suicidality [10-19]. The literature on seasonal variations in the occurrence of suicide is wide and contradictory. Conversely, the impact of individual or personality characteristics, such as meteotropism, has been rarely examined, although biological (the serotonin system) and sociological (opportunities, holidays, contingencies, etc.) factors have been investigated as potential predictors of suicidal behaviour [20].

Recently, sleep alterations have been identified as potential risk factors for suicidal ideation and attempts $[12,21,22]$. In the National Comorbidity Survey Replication (NCS-R), the relationship between three measures of sleep patterns (difficulty in initiating sleep, maintaining sleep, early morning awakening) and suicidal ideation, plans and attempts, was explored in a sample of 5692 US adults. Sleep problems were significantly associated with 
suicidal ideation $(\mathrm{OR}=2.1, \mathrm{CI}: 1.6-2.8)$, plans $(\mathrm{OR}=2.6$, CI: 1.4-4.9) and attempts ( $\mathrm{OR}=2.5, \mathrm{CI}: 1.2-5.2)$ [22]. Interestingly, the link between sleep problems and suicidal ideation or attempt seems to be relatively independent from the effect of psychiatric diagnoses [23-25].

Despite still scarce, some reports have explored alterations in rhythmicity and vegetative functions in PTSD. Solt et al. [26], investigating Vietnam veterans with PTSD admitted to a Veteran Hospital during a 3-year period, found admissions for PTSD to be significantly more frequent in spring and summer, suggesting the possibility that seasonal factors may influence PTSD. Sleep disturbances, including nightmares and insomnia, are core features of PTSD that likely contribute to the pathogenesis of the disorder and to poor daytime functioning [27-29]. Further, arousal regulation and memory consolidation appear to be important in determining the development of PTSD and both are functions of sleep. Somatic symptoms and sexual dysfunction may also be associated with PTSD [30-33]. Westermeyer et al. [34] explored four somatic symptoms (headaches, appetite change, dizziness, and sleep problems) in 622 Somali refugees finding significantly higher scores in survivors with PTSD, particularly those who experienced more types of trauma or higher symptoms scores.

In the framework of the Spectrum Project (a USAItaly collaboration), a questionnaire was developed and validated, that explores a full spectrum of lifetime mood spectrum phenomenology (Mood Spectrum-Self Report, MOODS-SR) [35] including dysregulations in rhythmicity and vegetative functions. The MOODS-SR rhythmicity and vegetative functions domain proved to be associated with suicidality in patients with schizophrenia and unipolar, bipolar, borderline personality and panic disorder [36]. Moreover, in a previous study some of us demonstrated that, amongst vegetative functions, dysregulations in sexual functioning and behavior are significantly associated with suicidality in patients with mood disorders [37].

The aim of the present study was to investigate dysregulations in rhythmicity and vegetative function, as assessed by the MOODS-SR, in patients with PTSD, and their impact on suicidality.

\section{Methods Design}

A consecutive sample of 65 out- and inpatients of both sexes (33 men and 32 women, mean age \pm SD: $45 \pm$ 14.8 years), with a DSM-IV-TR diagnosis of chronic PTSD, was recruited at the Section of Psychiatry of the Department of Clinical and Experimental Medicine, University of Pisa, Italy. Methods and sample characteristics were described in details in a previous study [38]. The majority of patients were married or living with a partner $(\mathrm{N}=37,56.9 \%)$, and had more than 8 years of education
$(\mathrm{N}=38, \quad 58.4 \%)$. Thirty-eight patients $(58.4 \%)$ were employed full-time or part-time and the remaining were unemployed or retired (see Table 1).

All subjects were reassessed for DSM diagnosis according to DSM-5 criteria by clinical researchers expert in the field.

The Ethics Committee of the Azienda OspedalieroUniversitaria of Pisa approved all recruitment and assessment procedures. Participants provided written informed consent, after receiving a complete description of the study and having the opportunity to ask questions.

\section{Diagnostic assessment}

Assessments included the SCID-IV-TR and the MOODSSR lifetime version.

The MOODS-SR, a questionnaire exploring mood spectrum symptomatology [35], includes 161 items coded as present/absent, for one or more periods of at least 3 to 5 days across the lifespan. Items are organized into 3 manic and 3 depressive domains, exploring "mood", "energy" and "cognition", besides a "rhythmicity and vegetative functions" domain. The manic and depressive domains focus on the presence of specific manic and depressive features respectively, including either isolated or clustered typical and atypical symptoms, traits and lifestyles that may characterize the temperamental affective dysregulations that make both fully syndromal

Table 1 Demographic characteristics of PTSD patients $(\mathrm{N}=65)$

\begin{tabular}{ll}
\hline & $\boldsymbol{N}(\%)$ \\
\hline Gender & $32(49.2)$ \\
Women & $33(50.8)$ \\
Men & \\
Marital status & $15(23.1)$ \\
Single & $37(56.9)$ \\
Married/living with partner & $4(6.2)$ \\
Widows-ers & $9(13.8)$ \\
Separated/divorced & \\
Educational level achieved & $9(13.8)$ \\
Primary school (5 years) & $18(27.7)$ \\
Secondary school (8 years) & $3(4.6)$ \\
Professional school (12 years) & $28(43.1)$ \\
High school diploma (13 years) & $7(10.8)$ \\
University degree (> = 16 years) & \\
Occupation & $38(58.4)$ \\
Employed & $6(9.2)$ \\
Unemployed & $13(20.0)$ \\
Retired & $8(12.4)$ \\
Other &
\end{tabular}


and subthreshold mood disturbances. The rhythmicity and vegetative functions domain includes 30 items organized into 5 subdomains that explore seasonal or circadian variations in mood and energy ("rhythmicity"), changes in weight/appetite, sexual activity, sleep and physical symptoms ("vegetative functions"). All MOODS-SR domains demonstrated a good internal consistency with KunderRichardson coefficients values always exceeding 0.79 [35].

The rhythmicity subdomain consists of 6 items investigating alterations in mood, energy and physical well-being according to the weather, the season, and the phase of menstrual cycle. The vegetative functions subdomains are: sleep (12 items), weight and appetite (4 items), sexual functions (5 items), physical symptoms (5 items, including headaches, dry mouth, constipation and stomach or bowel problems and sensitivity to heat, cold or pain). For the present study we excluded from the analyses two items of the sleep subdomain that explore alterations over the course of the menstrual cycle and apply only to females. The instrument can be downloaded from the web site www.spectrum-project.org. Suicidality is assessed using 6 items of the MOODS-SR that explore whether the subject had ever experienced periods of 3 to 5 days or more when he or she: thought that life is not worth living ( $N=102)$; wished he/she would not wake up in the morning, or that he/she would die in an accident or from something like a heart attack or a stroke ( $N=103)$; wanted to die or hurt him/herself $(N=104)$; wanted to die and had a specific plan to hurt or kill him/herself ( $N=105)$; actually committed a suicide attempt $(N=106)$; committed a suicide attempt that required medical attention $(N=107)$. For the purpose of the present study, suicidality was rated counting the positive answers to these questions.

\section{Statistical analyses}

Chi squared tests were utilized to compare the frequencies of endorsement of the rhythmicity and vegetative functions items of PTSD patients with at least one positive suicidal item on the MOODS-SR compared to those without suicidality. Student's t-tests were utilized to compare the same two groups for what concern rhythmicity and vegetative functions domain and subdomains scores. The relationship between suicidality and the rhythmicity and vegetative functions domain total score was investigated with an univariate linear regression analysis. The relationships between suicidality and the rhythmicity and vegetative function sub-domains scores were investigated by using a multiple linear stepwise regression model.

Statistical analyses were carried out using the Statistical Package for Social Science [39], version 20.0.

\section{Results}

At the index assessment, 20 (30.8\%) PTSD patients, out of the total of 65 , also met the DSM-5 criteria for major depression. On average, participants endorsed 10.2 items $(\mathrm{SD}=5.5)$ on the rhythmicity and vegetative functions domain.

The frequency of endorsement of suicidality items was: $46.2 \%$ (thought that life is not worth living); $27.7 \%$ (wished he/she would not to wake up in the morning, or that he/she would die in an accident or from something like a heart attack or a stroke); $35.4 \%$ (wanted to die or hurt him/herself); $10.8 \%$ (wanted to die, had a specific plan to hurt or kill him/herself); 12.3\% (actually committed a suicide attempt); and $7.7 \%$ (the attempt required medical attention).

The frequency of endorsement of rhythmicity and vegetative function items is reported in Table 2. The most frequently endorsed items were hypersensitivity to rhythm disruptions and sleep problems. In the same table the frequency of endorsement of the same items was compared between PTSD patients with at least one suicidal item with respect to those with no suicidality. Results showed significantly higher percentages in all the appetite/weight subdomain items and in about half of the sleep rhythmicity and physical symptoms sub-domain items. The comparisons between PTSD patients with at least one suicidal item with respect to those with no suicidality in the rhythmicity and vegetative functions domain total and subdomains scores are reported in Table 3. Statistically significant higher scores emerged in PTSD patients with at least one suicidal item in all scores.

A linear regression analysis showed a statistically significant association between the rhythmicity and vegetative functions domain scores and suicidality $[b=0.13$ $(\mathrm{SE}=0.03, \beta=0.45, \mathrm{t}=4.02, \mathrm{p}<0.001)$ ] (Figure 1).

An exploratory multiple linear regression analysis stepwise model was adopted in order to detect the most affecting subdomains. A significant association emerged between suicidality and first the appetite/weight subdomain and secondly the rhythmicity subdomain (see Table 4).

As the study group included 20 patients with a current episode of major depression and another 14 who had been suffering from past depressive, we hypothesized that the association between rhythmicity and vegetative functions symptoms and suicidality might be confounded by depression. Therefore, we preformed the linear regression analysis in the subsample of patients without current or past major depression. The rhythmicity and vegetative functions total score was still significantly associated with suicidality $[\mathrm{b}=0.09,(\mathrm{SE}=0.05, \beta=0.35, \mathrm{t}=2.04, \mathrm{p}=.05)]$.

\section{Discussion}

The results of the present study indicate high rates of impaired rhythmicity and vegetative functions, reported across the lifespan, in patients with PTSD. In particular, sleep problems and hypersensitivity to disruptions in 
Table 2 MOODS-SR rhythmicity and vegetative functions items endorsement in the total sample $(n=65)$ and in PTSD patients without MOODS-SR suicidal items $(n=29)$ with respect to those with at least 1 suicidal item $(n=36)$

\begin{tabular}{|c|c|c|c|c|c|}
\hline \multicolumn{2}{|c|}{ MOODS-SR rhythmicity item } & \multirow{2}{*}{$\begin{array}{l}\begin{array}{l}\text { Total } \\
\text { sample } \mathbf{N}(\%)\end{array} \\
17(26.2)\end{array}$} & \multirow{2}{*}{$\begin{array}{l}\text { No MOODS-SR } \\
\text { suicidal items } N(\%)\end{array}$} & \multirow{2}{*}{$\begin{array}{l}\geq 1 \text { MOODS-SR } \\
\text { suicidal item } \mathbf{N}(\%)\end{array}$} & \multirow{2}{*}{$\begin{array}{l}p \\
.237\end{array}$} \\
\hline 132 & Difficulty working in the early morning & & & & \\
\hline 133 & Difficulty working in the evening or night & $24(36.9)$ & $6(20.7)$ & $18(50.0)$ & .030 \\
\hline 134 & Irritable if daily routine is disrupted & $20(30.8)$ & $4(13.8)$ & $16(44.4)$ & .017 \\
\hline 135 & $\begin{array}{l}\text { Mood, energy, interest and efficiency improved if you were } \\
\text { in a regular routine }\end{array}$ & $36(55.4)$ & $13(44.8)$ & $23(63.9)$ & .199 \\
\hline 136 & More energetic with less sleep & $14(21.5)$ & $1(3.4)$ & $13(36.1)$ & .004 \\
\hline 137 & $\begin{array}{l}\text { Mood, energy and physical well-being changing with the } \\
\text { weather, season or when travelling across time zones }\end{array}$ & $42(64.6)$ & $16(55.2)$ & $26(72.2)$ & .243 \\
\hline \multicolumn{6}{|l|}{ Sleep } \\
\hline 138 & Sleepy all the time & $26(40.0)$ & $5(17.2)$ & $21(58.3)$ & .002 \\
\hline 139 & Repeated difficulty falling asleep & $42(64.6)$ & $14(48.3)$ & $28(77.8)$ & .027 \\
\hline 140 & Repeatedly waking up in the middle of the night & $42(64.6)$ & $13(44.8)$ & $29(80.6)$ & .006 \\
\hline 141 & Repeatedly waking up early & $38(58.5)$ & $12(41.4)$ & $26(72.2)$ & .024 \\
\hline 142 & Needing much more sleep than usual & $31(47.7)$ & $7(24.1)$ & $24(66.7)$ & .002 \\
\hline 143 & $\begin{array}{l}\text { You went for days without sleeping or with much less sleep } \\
\text { than usual but didn't feel tired? }\end{array}$ & $22(33.8)$ & $8(27.6)$ & $14(38.9)$ & .488 \\
\hline 144 & Difficulty sleeping before or after stimulating activities & $28(43.1)$ & $11(37.9)$ & $17(47.2)$ & 617 \\
\hline 145 & Increase in quality/need for sleep in a particular season & $25(38.5)$ & $6(20.7)$ & $19(52.85)$ & .017 \\
\hline 146 & $\begin{array}{l}\text { Increase in quality/need for sleep when traveling } \\
\text { across }>=4 \text { time zones }\end{array}$ & $8(12.3)$ & $4(13.8)$ & $4(11.1)$ & 1.00 \\
\hline 147 & $\begin{array}{l}\text { Decrease in quality/need for sleep when traveling } \\
\text { across }>=4 \text { time zones }\end{array}$ & $8(12.3)$ & $3(10.3)$ & $5(13.9)$ & .723 \\
\hline \multicolumn{6}{|c|}{ Appetite/Weight } \\
\hline 150 & No food appeals or tastes good & $23(35.4)$ & $6(20.7)$ & $17(47.2)$ & .050 \\
\hline 151 & Constantly craving for sweets or carbohydrates & $20(30.8)$ & $3(10.3)$ & $17(47.2)$ & .003 \\
\hline 152 & Appetite/weight increased & $16(24.6)$ & $2(6.9)$ & $14(38.9)$ & .007 \\
\hline 153 & Appetite/weight decreased & $21(32.3)$ & $3(10.3)$ & $18(50.0)$ & .002 \\
\hline \multicolumn{6}{|c|}{ Sexual function } \\
\hline 154 & Less sexually active than usual & $27(41.5)$ & $7(24.1)$ & $20(55.6)$ & .021 \\
\hline 155 & Difficulty becoming sexually aroused & $25(38.5)$ & $7(24.1)$ & $18(50.0)$ & .061 \\
\hline 156 & Difficulty achieving orgasm & $13(20.0)$ & $5(17.2)$ & $8(22.2)$ & .852 \\
\hline 157 & More interested in sex & $11(16.9)$ & $2(6.9)$ & $9(25.0)$ & .109 \\
\hline 158 & Frequently changing sexual partners & $8(12.3)$ & $1(3.4)$ & $7(19.4)$ & .066 \\
\hline \multicolumn{6}{|c|}{ Physical symptoms } \\
\hline $159 \mathrm{~A}$ & Frequent headaches & $25(38.5)$ & $5(17.2)$ & $20(55.6)$ & .004 \\
\hline $159 B$ & Dry mouth & $27(41.5)$ & $5(17.2)$ & $22(61.1)$ & .001 \\
\hline $159 C$ & Constipation & $20(30.8)$ & $7(24.1)$ & $13(36.1)$ & .442 \\
\hline $159 D$ & Nausea or other Gl problems & $25(38.5)$ & $7(24.1)$ & $18(50.0)$ & .061 \\
\hline 160 & More/less sensitive than usual to heat, cold or pain & $29(44.6)$ & $6(20.7)$ & $23(63.9)$ & .001 \\
\hline
\end{tabular}

circadian and/or seasonal rhythms were the most frequent, with more than half of the patients reporting such symptoms.

Sleep disturbances represent a core feature of PTSD. Nightmares and insomnia are diagnostic symptoms of
PTSD (DSM-5) [40-42] and other sleep disturbances, such as sleep avoidance, sleep terrors, nocturnal anxiety attacks, simple and complex motor behaviors and vocalizations, acting out dreams, sleep apnea and periodic leg movement disorders, are also frequently reported by and 
Table 3 MOODS-SR rhythmicity and vegetative functions domain and subdomains scores in PTSD patients without MOODS-SR suicidal items $(n=29)$ compared with those with at least 1 suicidal item $(n=36)$

\begin{tabular}{llll}
\hline $\begin{array}{l}\text { MOODS-SR rhythmicity } \\
\text { and vegetative } \\
\text { functions domain }\end{array}$ & $\begin{array}{l}\text { No MOODS-SR } \\
\text { suicidal items } \\
\text { (mean } \pm \text { SD) }\end{array}$ & $\begin{array}{l}\mathbf{z} \text { MOODS-SR } \\
\text { suicidal item } \\
\text { (mean } \pm \text { SD) }\end{array}$ & $\boldsymbol{p}$ \\
\hline Total score & $6.34 \pm 4.48$ & $13.33 \pm 4.20$ & $<.001$ \\
Subdomains & $1.55 \pm 1.33$ & $3.00 \pm 1.59$ & $<.001$ \\
Rhytmicity & $2.86 \pm 2.26$ & $5.19 \pm 2.01$ & $<.001$ \\
Sleep & $0.48 \pm 0.87$ & $1.83 \pm 1.16$ & $<.001$ \\
Appetite/weight & $1.04 \pm 1.70$ & $2.67 \pm 1.88$ & .001 \\
Physical symptoms & $0.76 \pm 1.12$ & $1.72 \pm 1.23$ & .002 \\
\hline Sexual function & & &
\end{tabular}

observed in PTSD patients [43-45]. Despite a major limitation of the present study is the use of a lifetime instrument such as the MOODS-SR that does not allow discriminating whether sleep disturbances occurred before or after the trauma exposure, we can speculate that patients at higher suicidal risk are more prone to report sleep problems across the lifespan. In this regards, subjective and objective sleep disturbances occurring early after trauma exposure have been reported to be associated with an increased risk for meeting criteria for PTSD at subsequent assessments conducted one year later [46,47]. Previous data have shown that sleep disturbances exacerbate daytime symptoms and contribute to poor outcomes in PTSD, such as increased severity of depression, suicidality, and general physical distress, poorer quality of life and functioning, poorer perceived physical health and increased alcohol or drug use [45,48-51]. Our results may be considered consistent with these previous findings giving further evidence that lifetime sleep disturbances are predictive of increased suicidal ideations in PTSD.

While little is known on alterations in rhythmicity in patients with PTSD, several authors highlighted the association between alterations in circadian and/or seasonal rhythms and suicide. Increased sensitivity to changes in weather and season has been related to higher risk for suicide in the general population $[11,17,20]$, but to the best of our knowledge, this is the first study focusing on the presence and impact of such symptoms in PTSD patients. Results from previous studies based on the MOODS-SR assessment, indicate a positive association between the number of lifetime rhythmicity and vegetative functions dysregulations and an increased risk for suicidal ideation/ plans in patients with unipolar depression and borderline personality disorder. Our data are in line with studies suggesting that higher levels of suicidality are related not so much to the weather or the season "per se" but rather to the peculiar sensitivity to changes of weather and season [36].

It is noteworthy that our correlations were confirmed even after controlling for depressive comorbidity suggesting

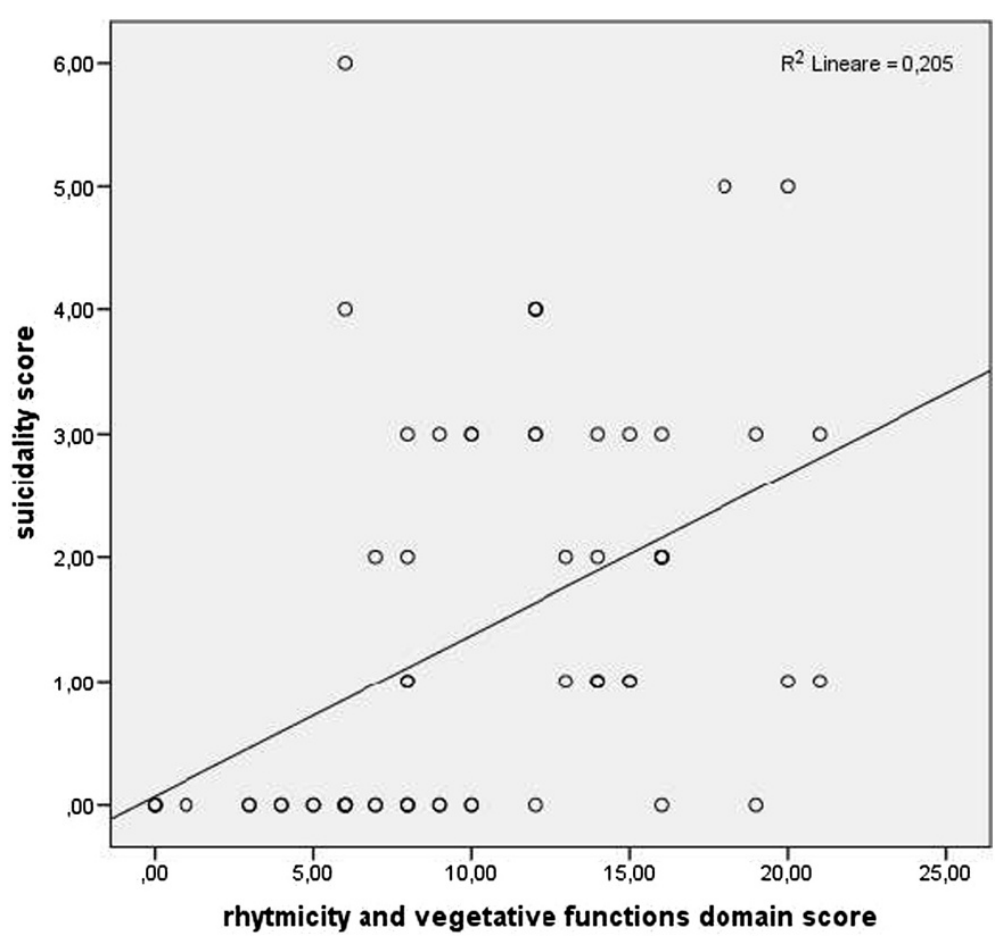

Figure 1 Association between MOODS-SR rhythmicity and vegetative functions domain score and suicidality. 
Table 4 Stepwise multiple linear regression analysis in 65 PTSD patients: MOODS-SR rhythmicity subdomains scores predicting suicidality

\begin{tabular}{lllllll}
\hline Step & $\begin{array}{l}\text { MOOD-SR rhythmicity } \\
\text { subdomain scores }\end{array}$ & $\boldsymbol{b}(\mathrm{SE})$ & $\boldsymbol{B}$ & $\boldsymbol{R}^{\mathbf{2}}$ & $\boldsymbol{t}$ & $\boldsymbol{p}$ \\
\hline 1 & Constant & $0.605(0.246)$ & & .249 & 2.46 & .016 \\
& Appetite & $0.646(0.141)$ & .499 & & 4.57 & $<.001$ \\
2 & Constant & $0.056(0.316)$ & & .323 & 0.18 & .0861 \\
& Appetite & $0.571(0.138)$ & .441 & & 4.13 & $<.001$ \\
& Rhythmicity & $0.272(0.105)$ & .278 & & 2.61 & .011 \\
\hline
\end{tabular}

the role of lifetime disturbances in rhythmicity as a possible correlate of suicidality in PTSD patients independently from mood disorder comorbidity. There is evidence that mood disorders, and particularly bipolar disorders, are sensitive to the environmental influence in general and to the seasonal effect in specific, and frequently report alterations in vegetative functions such as sleep, appetite, and sexual functions [52-56]. Thus, our data suggest a lifetime subthreshold bipolar comorbidity to be related to a higher suicidality in PTSD, similarly to what happens for comorbidity with full blown bipolar disorder [57-59]. Consistently, in a previous report on PTSD patients without bipolar disorder comorbidity, we found statistically significant and positive associations between manic/hypomanic and depressive symptoms and the likelihood of suicidal ideation or attempts suggesting an impact of even subthreshold forms of bipolar disorder [60]. Similarly, other authors suggested theoretical models highlighting clinical symptoms that could lead to suicidality (i.e., through feelings of hopelessness, defeat and entrapment) [61,62].

Different data would indicate a relationship between a specific and particularly severe trauma, such as childhood sexual abuse (CSA), and abnormal eating attitudes and behaviors $[63,64]$. The same association has been reported with other forms of victimization, trauma and neglect, including, but being not limited to, sexual assault [65-67]. In sum, these studies suggest that any experience that can produce PTSD may increase the probability of developing threshold or subthreshold eating disorders. On this line, some authors hypothesized that eating disorders could represent, for a traumatized patient, an attempt to regulate the overwhelming affective states, and that bingeing and purging may be used in order to control PTSD symptomathology $[68,69]$. Our findings, besides showing the high occurrence of changes in weight and appetite in PTSD patients, suggest that these symptoms may confer a greater risk for suicidal ideation and suicide attempts across the lifespan, irrespective of previous or current major depression, and that they should be carefully considered during the routine clinical assessment. It is noteworthy that the link between diagnosable eating disorders and suicidal behaviors has been recognized for some time [65], whereas recent evidence from studies in adolescents suggests a correlation between suicidal behavior and disordered eating behaviors that fall short of the threshold for an eating disorder diagnosis [66,67]. Our data extend this evidence to adults, and taken together, stress the increased risk for suicide in those adult PTSD patients displaying eating changes in weight and appetite, which should be therefore. We could also argue that the links between alterations in appetite and/or weight and suicide attempts point towards some role for disturbed serotonergic neurotransmission, since changes in appetite and craving for sweets and carbohydrates can be influenced by serotonin. Moreover, these symptoms frequently occur in patients with bipolar disorder, and this might be a further indicator of soft bipolarity in these patients [70-72].

Several limitations of the study are important to note. First of all, as already mentioned, this was a crosssectional study in which the use of a lifetime assessment does not allow establishing whether the alterations in rhythmicity and vegetative function preceded or cooccurred with suicidal ideation or attempts. No data, in fact, was collected in the study that could provide information as to whether a temporal association exists between these two variables. Second, rhythmicity and vegetative functions symptoms were assessed by means of a self-report and this may be less reliable than objective observations. Matousek et al. [73] reported poor agreement between the subjective and objective assessment of disturbed night sleep and alertness in the daytime in a sample of patients with mild depression, suggesting a significant influence of anxiety and depression on these reports. Similarly, the presence of suicidal ideation or attempts was not assessed through the rating of the clinician, so that a self-report of suicidality may be considered less accurate. In any case, literature data comparing selfreports and clinical assessment of suicidal symptoms indicate that self-rating of suicidality contains considerable predictive value and should be the primary data source [38]. A further limitation relates to the measure of suicidal ideation used in study. This measure was a composite score of a range of behaviors including wishes of death, suicidal ideation and planning. Particularly, wishes of deaths might represent different phenomena from suicidal thoughts and plans and, although the continuum view of suicidality has received support by recent studies [74], this may represent an important methodological limitation. Third, the sample size was small, although with a similar number of men and women. Fourth, because the MOODS-SR is a lifetime assessment we could not determine whether an ongoing drug treatment might have 
influenced the alterations in weight and/or appetite reported. Fifth, the lack of information on the characteristics of the index trauma (e.g. severity, degree of exposure, length of exposure) and of PTSD in terms of chronicity of the illness, may affect the results of the present study as they could not be generalizable to all categories of patients diagnosed with PTSD.

\section{Conclusions}

In conclusion, despite taking into account the limitations mentioned above, our results suggest that impaired rhythmicity and vegetative functions correlate with lifetime suicidality in PTSD patients. Therefore, our data highlight the need to explore these functions in PTSD patients across the lifespan, in order to identify as soon as possible individuals at higher suicidal risk.

\section{Competing interests}

The authors declare that they have no competing interests.

\section{Authors' contributions}

LDO and CCar participated to the conception and design of the study, the interpretation of data and draft of the article. GM performed statistical analysis. MC, VR and CCon participated to the interpretation of data and critical revision of the article. CAB participated to the critical revision of the article and literature research. All authors read and approved the final manuscript.

\section{Author details}

'Section of Psychiatry, Department of Clinical and Experimental Medicine, University of Pisa, Via Roma 67, Pisa 56126, Italy. ${ }^{2}$ Department of Public Health, University of Cagliari, Cagliari, Italy. ${ }^{3}$ Department of Neuropsychiatry, University of Florence, Florence, Italy.

Received: 10 August 2014 Accepted: 25 November 2014 Published online: 12 December 2014

\section{References}

1. Kessler RC: Posttraumatic stress disorder: the burden to the individual and to society. J Clin Psychiatry 2000, 61:4-12.

2. Carmassi C, Dell'Osso L, Manni C, Candini V, Dagani J, lozzino L, Koenen KC, de Girolamo G: Frequency of trauma exposure and Post-Traumatic Stress Disorder in Italy: analysis from the World Mental Health Survey Initiative. J Psychiatr Res 2014, 59:77-84.

3. Hussain A, Weisæth L, Heir T: Posttraumatic stress and symptom improvement in Norwegian tourists exposed to the 2004 tsunami-a longitudinal study. BMC Psychiatry 2013, 13:232.

4. $\quad \mathrm{Wu} \mathrm{Z}, \mathrm{Xu} \mathrm{J}, \mathrm{He} \mathrm{L}$ : Psychological consequences and associated risk factors among adult survivors of the 2008 Wenchuan earthquake. BMC Psychiatry 2014, 14(1):126.

5. Dell'Osso L, Carmassi C, Massimetti G, Daneluzzo E, Di Tommaso S, Rossi A: Full and partial PTSD among young adult survivors 10 months after the L'Aquila 2009 earthquake: gender differences. J Affect Disord 2011, 131(1-3):79-83.

6. Dell'Osso L, Carmassi C, Stratta P, Massimetti G, Akiskal KK, Akiskal HS, Maremmani I, Rossi A: Gender Differences in the Relationship between Maladaptive Behaviors and Post-Traumatic Stress Disorder. A Study on 900 L' Aquila 2009 Earthquake Survivors. Front Psychiatry 2013, 4(3):111.

7. Carmassi C, Akiskal HS, Yong SS, Stratta P, Calderani E, Massimetti E, Akiskal KK, Rossi A, Dell'Osso L: Post-traumatic stress disorder in DSM-5: estimates of prevalence and criteria comparison versus DSM-IV-TR in a non-clinical sample of earthquake survivors. J Affect Disord 2013, 151(3):843-848.

8. Carmassi C, Akiskal HS, Bessonov D, Massimetti G, Calderani E, Stratta P, Rossi A, Dell'Osso L: Gender differences in DSM-5 versus DSM-IV-TR PTSD prevalence and criteria comparison among 512 survivors to the L'Aquila earthquake. J Affect Disord 2014, 160:55-61.
9. Dell'Osso L, Carmassi C, Massimetti G, Stratta P, Riccardi I, Capanna C, Akiskal KK, Akiskal HS, Rossi A: Age, gender and epicenter proximity effects on post-traumatic stress symptoms in L'Aquila 2009 earthquake survivors. J Affect Disord 2013, 146(2):174-180.

10. Biermann T, Estel D, Sperling W, Bleich S, Kornhuber J, Reulbach U: Influence of lunar phases on suicide: the end of a myth? A populationbased study. Chronobiol Int 2005, 22(suppl 6):1137-1143.

11. Lee HC, Lin HC, Tsai SY, Li CY, Chen CC, Huang CC: Suicide rates and the association with climate: a population-based study. J Affect Disord 2006, 92:221-226.

12. Liu X, Buysse DJ: Sleep and youth suicidal behavior: a neglected field. Curr Opin Psychiatry 2006, 19:288-293.

13. Benedito-Silva AA, Pires ML, Calil HM: Seasonal variation of suicide in Brazil. Chronobiol Int 2007, 24:727-737.

14. Voracek M, Tran US, Sonneck G: Facts and myths about seasonal variation in suicide. Psychol Rep 2007, 100:810-814.

15. Maes M, Cosyns P, Meltzer HY, De Meyer F, Peeters D: Seasonality in violent suicide but not in nonviolent suicide or homicide. Am J Psychiatry 1993, 150(suppl 9):1380-1385.

16. Preti $A$ : The influence of seasonal change on suicidal behavior in Italy. J Affect Disord 1997, 44(suppl 2-3):123-130.

17. Altamura C, VanGastel A, Pioli R, Mannu P, Maes M: Seasonal and circadian rhythms in suicide in Cagliari, Italy. J Affect Disord 1999, 53:77-85.

18. Morken G, Lilleeng S, Linaker OM: Seasonal variation in suicides and in admissions to hospital for mania and depression. J Affect Disord 2002, 69(suppl 1):39-45

19. Björkstén KS, Kripke DF, Bjerregaard P: Accentuation of suicides but not homicides with rising latitudes of Greenland in the sunny months. BMC Psychiatry. 2009, 8:9-20.

20. Preti A, Miotto P, De Coppi M: Season and suicide: recent findings from Italy. Crisis 2000, 21:59-70.

21. Goldstein TR, Bridge JA, Brent DA: Sleep disturbance preceding completed suicide in adolescents. J Consult Clin Psychol 2008, 76:84-91.

22. Wojnar M, Ilgen MA, Wojnar J, McCammon RJ, Valenstein M, Brower KJ: Sleep problems and suicidality in the National Comorbidity Survey Replication. J Psychiatr Res 2009, 43:526-531.

23. Bernert RA, Joiner TE Jr, Cukrowicz KC, Schmidt NB, Krakow B: Suicidality and sleep disturbances. Sleep 2005, 28:1135-1141.

24. Chellappa SL, Araújo JF: Sleep disorders and suicidal ideation in patients with depressive disorder. Psychiatry Res 2007, 153:131-136.

25. Goodwin RD, Marusic A: Association between short sleep and suicidal ideation and suicide attempt among adults in the general population. Sleep 2008, 31:1097-1101.

26. Solt V, Chen CJ, Roy A: Seasonal pattern of posttraumatic stress disorder admissions. Compr Psychiatry 1996, 37(1):40-42.

27. Mellman TA, Bustamante V, Fins Al, Pigeon WR, Nolan B: REM sleep and the early development of posttraumatic stress disorder. Am J Psychiatry 2002, 159:1696-1701.

28. Mellman TA, Hipolito MM: Sleep disturbances in the aftermath of trauma and posttraumatic stress disorder. CNS Spectr 2006, 11(8):611-615. Review.

29. Germain A, Buysse DJ, Nofzinger E: Sleep-specific mechanisms underlying posttraumatic stress disorder: integrative review and neurobiological hypotheses. Sleep Med Rev 2008, 12:185-195.

30. Letourneau EJ, Schewe PA, Frueh BC: Preliminary evaluation of sexual problems in combat veterans with PTSD. J Trauma Stress 1997, 10(1):125-132.

31. Kotler M, Cohen H, Aizenberg D, Matar M, Loewenthal U, Kaplan Z, Miodownik $H$, Zemishlany Z: Sexual dysfunction in male posttraumatic stress disorder patients. Psychother Psychosom 2000, 69(6):309-315.

32. Westermeyer J, Khawaja IS, Freerks M, Sutherland RJ, Engle K, Johnson D, Thuras P, Rossom R, Hurwitz T: Quality of sleep in patients with posttraumatic stress disorder. Psychiatry (Edgmont) 2010, 7(9):21-27.

33. Gupta MA: Review of somatic symptoms in post-traumatic stress disorder. Int Rev Psychiatry 2013, 25(1):86-99.

34. Westermeyer J, Khawaja I, Freerks M, Sutherland RJ, Engle K, Johnson D, Thuras P, Rossom R, Hurwitz T: Correlates of daytime sleepiness in patients with posttraumatic stress disorder and sleep disturbance. Prim Care Companion J Clin Psychiatry 2010, 12(2):e1-e6.

35. Dell'Osso L, Armani A, Rucci P, Frank E, Fagiolini A, Corretti G, Shear MK, Grochocinski VJ, Maser JD, Endicott J, Cassano GB: Measuring mood spectrum: comparison of interview (SCI-MOODS) and self-report (MOODS-SR) instruments. Compr Psychiatry 2002, 43:69-73. 
36. Balestrieri M, Rucci P, Sbrana A, Ravani L, Benvenuti A, Gonnelli C, Dell'Osso L, Cassano GB: Lifetime rhythmicity and mania as correlates of suicidal ideation and attempts in mood disorders. Compr Psychiatry 2006, 47:334-341.

37. Dell'Osso L, Carmassi C, Carlini M, Rucci P, Torri P, Cesari D, Landi $P$, Ciapparelli A: Sexual dysfunctions and suicidality in patients with bipolar I disorder and unipolar depression. J Sex Med 2009, 6(suppl 11):3063-3070.

38. Dell'Osso L, Carmassi C, Rucci P, Ciapparelli A, Paggini R, Ramacciotti CE, Conversano C, Balestrieri M, Marazziti D: Lifetime Subthreshold Mania is Related to Suicidality in Posttraumatic Stress Disorder. CNS Spectr 2009, 14(5):262-266.

39. IBM Corp: Released 2010. IBM SPSS Statistics for Windows, Version 19.0. Armonk, NY: IBM Corp

40. Friedman MJ, Resick PA, Bryant RA, Brewin CR: Considering PTSD for DSM-5. Depress Anxiet. 2011, 28(9):750-769.

41. Hinton DE, Lewis-Fernández R: The cross-cultural validity of posttraumatic stress disorder: implications for DSM-5. Depress Anxiety 2011, 28(9):783-801.

42. American Psychiatric Association: Diagnostic and Statistical Manual of Mental Disorders: DSM-5. Washington, DC: Amer Psychiatric Pub Incorporated; 2013.

43. Germain A, Hall M, Krakow B, Shear MK, Buysse DJ: A brief sleep scale for posttraumatic stress disorder: Pittsburgh Sleep Quality Index Addendum for PTSD. J Anxiety Disord 2005, 19:233-244.

44. Krakow B, Artar A, Warner TD, Melendrez D, Johnston L, Hollifield M, Germain A, Koss M: Sleep disorder, depression, and suicidality in female sexual assault survivors. Crisis 2000, 21:163-170.

45. Koren D, Arnon I, Lavie P, Klein E: Sleep complaints as early predictors of posttraumatic stress disorder: a 1-year prospective study of injured survivors of motor vehicle accidents. Am J Psychiatry 2002, 159:855-857.

46. Krakow B, Melendrez D, Johnston L, Warner TD, Clark JO, Pacheco M, Pedersen B, Koss M, Hollifield M, Schrader R: Sleep-disordered breathing, psychiatric distress, and quality of life impairment in sexual assault survivors. J Nerv Ment Dis 2002, 190:442-452.

47. Clum GA, Nishith P, Resick PA: Trauma-related sleep disturbance and selfreported physical health symptoms in treatment-seeking female rape victims. J Nerv Ment Dis 2001, 189:618-622.

48. Nishith P, Resick PA, Mueser KT: Sleep difficulties and alcohol use motives in female rape victims with posttraumatic stress disorder. J Trauma Stress 2001, 14:469-479.

49. Saladin ME, Brady KT, Dansky BS, Kilpatrick DG: Understanding comorbidity between PTSD and substance use disorders: two preliminary investigations. Addict Behav 1995, 20:643-655.

50. Hakkarainen R, Johansson C, Kieseppä T, Partonen T, Koskenvuo M, Kaprio J, Lönnqvist J: Seasonal changes, sleep length and circadian preference among twins with bipolar disorder. BMC Psychiatry 2003, 3:6.

51. Murray G, Harvey A: Circadian rhythms and sleep in bipolar disorder. Bipolar Disord 2010, 12(suppl 5):459-472.

52. Bellivier F, Yon L, Luquiens A, Azorin JM, Bertsch J, Gerard S, Reed C, Lukasiewicz M: Suicidal attempts in bipolar disorder: results from an observational study (EMBLEM). Bipolar Disord 2011, 13(suppl 4):377-386.

53. Nordentoft M: Crucial elements in suicide prevention strategies. Prog Neuropsychopharmacol Biol Psychiatry 2011, 35(suppl 4):848-853.

54. Parmentier C, Etain B, Yon L, Misson H, Mathieu F, Lajnef M, Cochet B, Raust A, Kahn JP, Wajsbrot-Elgrabli O, Cohen R, Henry C, Leboyer M, Bellivier F: Clinical and dimensional characteristics of euthymic bipolar patients with or without suicidal. Eur Psychiatry 2011, [Epub ahead of print].

55. Kessler RC, Borges G, Walters EE: Prevalence of and risk factors for lifetime suicide attempts in the National Comorbidity Survey. Arch Gen Psychiatry 1999, 56:617-626.

56. Bauer MS, Altshuler L, Evans DR, Beresford T, Williford WO, Hauger R: Cooperative Study 430 Team. Prevalence and distinct correlates of anxiety, substance, and combined comorbidity in a multi-site public sector sample with bipolar disorder. J Affect Disord 2005, 85:301-315.

57. Quarantini LC, Miranda-Scippa A, Nery-Fernandes F, Andrade-Nascimento M, Galvão-de-Almeida A, Guimarães JL, Teles CA, Netto LR, Lira SB, de Oliveira IR, Post RM, Kapczinski F, Koenen KC: The impact of comorbid posttraumatic stress disorder on bipolar disorder patients. J Affect Disord 2010, 123(suppl 1-3):71-76.

58. Dell'Osso L, Stratta P, Conversano C, Massimetti E, Akiskal KK, Akiskal HS, Rossi A, Carmassi C: Lifetime mania is related to post-traumatic stress symptoms in high school students exposed to the 2009 L'Aquila earthquake. Compr Psychiatry 2014, 55(suppl 2):357-362.
59. Jacobi C, Hayward C, de Zwaan M, Kraemer H, Agras WS: Coming to terms with risk factors for eating disorders: Application of risk terminology and suggestions for a general taxonomy. Psychol Bull 2004, 130:19-65.

60. Brewerton TD: Psychological trauma and eating disorders. Eur Eat Disord Rev 2005, 1:137-154

61. Panagioti M, Gooding PA, Tarrier N: Hopelessness, defeat, and entrapment in posttraumatic stress disorder: their association with suicidal behavior and severity of depression. J Nerv Ment Dis 2012, 200(8):676-683.

62. Panagioti M, Gooding PA, Tarrier N: A prospective study of suicidal ideation in posttraumatic stress disorder: the role of perceptions of defeat and entrapment. J Clin Psychol 2014, doi: 10.1002/jclp.22103.

63. Dansky BS, Brewerton TD, O'Neil PM, Kilpatrick DG: The National Women's Study: Relationship of crime victimization and PTSD to bulimia nervosa. Int J Eat Disord 1997, 21:213-228.

64. Johnson JG, Cohen P, Kasen S, Brook JS: Childhood adversities associated with risk for eating disorders or weight problems during adolescence or early adulthood. Am J Psychiatry 2002, 159:394-400.

65. Faravelli C, Giugni A, Salvatori S, Ricca V: Psychopathology after rape. Am J Psychiatry 2004, 161:1483-1485.

66. Rorty M, Yager J: Histories of childhood trauma and complex post-traumatic sequelae in women with eating disorders. Psychiatr Clin North Am 1996, 19:773-791.

67. Franko DL, Keel PK: Suicidality in eating disorders: occurrence, correlates, and clinical implications. Clin Psychol Rev 2006, 26(6):769-782.

68. Ackard DM, Neumark-Sztainer D, Story M, Perry C: Overeating among adolescents: Prevalence and associations with weight-related characteristics and psychological health. Pediatrics 2003, 111:67-74.

69. Carmassi C, Antonio Bertelloni C, Massimetti G, Miniati M, Stratta P, Rossi A Dell'Osso L: Impact of DSM-5 PTSD and gender on impaired eating behaviors in 512 Italian earthquake survivors. Psychiatry Res 2015, 225(1-2):64-69.

70. Crow S, Eisenberg ME, Story M, Neumark-Sztainer D: Suicidal behavior in adolescents: Relationship to weight status, weight control behaviors, and body dissatisfaction. Int J Eat Disord 2008, 41:82-87.

71. Miotto P, De Coppi M, Frezze M, Preti A: Eating disorders and suicide risk factors in adolescents: An Italian community-based study. J Nerv Ment Dis 2003, 191:962-966.

72. Miotto P, Preti A: Eating disorders and suicide ideation: the mediating role of depression and aggressiveness. Compr Psychiatry 2007, 48:218-224.

73. Matousek M, Cervena K, Zavesicka L, Brunovsky M: Subjective and objective evaluation of alertness and sleep quality in depressed patients. BMC PsyC hiatry 2004, 26:4-14.

74. Bebbington PE, Minot S, Cooper C, Dennis M, Meltzer H, Jenkins R, Brugha T: Suicidal ideation, self-harm and attempted suicide: results from the British psychiatric morbidity survey 2000. Eur Psychiatry 2010, 25(7):427-431.

\section{Submit your next manuscript to BioMed Central and take full advantage of:}

- Convenient online submission

- Thorough peer review

- No space constraints or color figure charges

- Immediate publication on acceptance

- Inclusion in PubMed, CAS, Scopus and Google Scholar

- Research which is freely available for redistribution 